
\title{
El paisaje sonoro como arte sonoro*
}

\section{Ana María Botella Nicolás}

El concepto de paisaje sonoro o soundscape acuñado por primera vez por el canadiense R. Murray Schafer en 1933 se basa en la defensa del valor del silencio y del sonido por sí mismo como fuente de creatividad. El objetivo principal del artículo es reflexionar sobre el concepto de paisaje sonoro como arte sonoro y reseñar las sinergias entre naturaleza y paisaje a través de la concepción de estos en la historia. Se plantea la paradoja del ruido como música y la incógnita del orden primigenio del sonido. Se incide en el valor emocional del paisaje sonoro y su utilidad como herramienta didáctica. Cuando se comprende la noción de Pauline Oliveros (1932-2016) con la escucha profunda y la falta de práctica de la escucha activa, se pone de manifiesto la pérdida de instintos naturales de los humanos. También se pone en valor la utilidad para monitorear la naturaleza, de estricta necesidad en los últimos tiempos. Y, en especial, se refleja el arte que proviene de ese marco natural. Para ello, se ha utilizado el análisis del discurso como metodología, apoyada en artistas sonoros como Murray Schafer o John Cage, pero también en José Val del Omar o en Llorenç Barber, músicos que abrieron nuevas formas y percepciones del sonido, por ende, ajenos a cánones clásicos y academicistas. Las conclusiones apuntan a que no es fácil encontrar el nuevo arte transversal en auditorios de programación regular, pero sí en festivales específicos y, en especial, a nuestro alrededor, en la naturaleza.

Palabras clave: arte sonoro, paisaje sonoro, didáctica de la música, escucha doi 10.11144/javeriana.mavae15-1.epsc

Fecha de recepción: 6 de julio de 2019

Fecha de aceptación: 17 de julio de 2019

Disponible en línea: 1 de enero de 2020

* El artículo es fruto de los resultados del proyecto de investigación I+D+i GV 2017/95 El paisaje sonoro, escucha, creación y recreación: análisis de escenarios de educación ambiental y musical de la Conselleria d'Educació, Investigació, Cultura i Esport de la Generalitat Valenciana.

** Licenciada en Geografía e Historia, especialista en Musicología y magíster en Educación Musical por la Universidad de Oviedo, y doctora en Pedagogía por la Universitat de València. Profesora de la Facultad de Magisterio de la Universitat de València.

ORCID: 0000-0001-5324-7152

Correo electrónico: ana.maria.botella04@uv.es

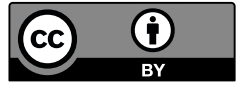




\section{The Soundscape as Sound Art}

The concept of soundscape, originally coined by Canadian R. Murray Schafer (1933), is based on the defense of the value of silence and of sound itself as a source of creativity (Schafer 2011, 2012). The main objective of the article is to reflect on the concept of soundscape as sound art and to review the synergies between nature and landscape through the notion of them throughout history. It presents the paradox of noise as music and the mystery of the original order of sound. It has a bearing on the emotional value of the sound landscape and its usefulness as a teaching tool. When the notion of Pauline Oliveros (1932-2016) is understood with profound listening and the lack of practice of active listening, the loss of natural instincts of humans is revealed. The utility to monitor nature, strictly necessary in recent times, is also valued. In particular, the art originating from that natural context is reflected. For this purpose, discourse analysis has been used as a methodology, supported by sound artists such as Murray Schafer or John Cage, but also in José Val del Omar or Llorenç Barber, musicians who opened new forms and perceptions of sound, therefore, others to classical and academic canons. The conclusions suggest that it is not easy to find the new transversal art in regular programming audiences, but in specific festivals and especially around us, in nature.

Keywords: sound art, soundscape, didactic music, listening

\section{A paisagem sonora como Arte Sonoro}

0 conceito de Paisagem Sonora ou soundscape, cunhada pela primeira vez pelo canadense R. Murray Schafer (1933), se baseia na defesa do valor do silêncio e do som por si mesmo como fonte de criatividade (Schafer 2011, 2012). 0 objetivo principal do artigo é refletir sobre o conceito de paisagem sonora como arte sonora e rever as sinergias entre natureza e paisagem através da concepção das mesmas na história. Considera-se o paradoxo do ruído como música e a incógnita da ordem primordial do som. Isso afeta o valor emocional da paisagem sonora e sua utilidade como ferramenta didática. Quando se compreende a noção de Pauline Oliveros (1932-2016) com a escuta profunda e a falta de prática da escuta ativa, é revelada a perda de instintos naturais dos humanos. Também é valorizada a utilidade para monitorar a natureza, de estrita necessidade nos últimos tempos. E, especialmente, se reflete a arte que vem desse marco natural. Para isso, tem-se utilizado a análise do discurso como metodologia, apoiada em artistas sonoros como Murray Schafer ou John Cage, mas também em José Val del Omar ou em Llorenç Barber, músicos que abriram novas formas e percepções do som, portanto, alheios a cânones clássicos e acadêmicos. As conclusões sugerem que não é fácil encontrar a nova arte transversal em auditórios de programação regular, mas sim em festivais específicos e especialmente ao nosso redor, na natureza.

Palavras-chave: arte sonora, paisagem sonora, didática da música, escuta 


\section{Aproximación al paisaje sonoro}

> La música clásica occidental o convencional es el resultado de los sonidos ordenados de uno o varios instrumentos musicales o voces. Usemos esta escueta y atrevida definición como punto de partida del artículo. Los instrumentos han ido evolucionando conforme al devenir de la humanidad, así como las formas musicales. Pero ese orden primigenio de los sonidos ¿fue un invento humano o un descubrimiento propio de la naturaleza? Realicemos un breve repaso a la historiografía del paisaje y al arte sonoro, veamos sus elementos y herramientas principales, y así podremos concluir por qué el paisaje deviene arte y por qué el problema ambiental nos afecta en esta vertiente.

El concepto de paisaje sonoro o soundscape acuñado por el canadiense R. Murray Schafer en 1933 se refiere a todo aquello que, "dentro del medio ambiente sonoro, puede percibirse como una unidad estética" (citado en Carles 2019). Schafer (2011, 2012) se basa en la defensa del valor del silencio y del sonido por sí mismo como fuente de creatividad (insiste en la necesidad de escuchar el silencio y saber apreciarlo). En palabras de Schafer (2011, 14), “la nueva orquesta es el universo sónico, y los nuevos músicos cualquiera u cualquier cosa que suene". Introduce el término paisaje sonoro para hacer que sus alumnos tomen conciencia de la contaminación acústica en la que están inmersos en muchas ocasiones. El paisaje sonoro es, por tanto, un sonido o una combinación de estos o también las formas que surgen de una inmersión en el medio ambiente (Botella y Hurtado 2016).

Pauline Oliveros (1932-2016), compositora e improvisadora, nos habla también de una escucha profunda que debemos practicar día a día y en todo momento. Oliveros está completamente desligada del filtro tecnológico, y es quizá la primera artista sonora, junto con Max Neuhaus (1939-2009) y Murray Schafer, en haber desarrollado un arte de la escucha (Rocha 2019).

Por su parte, Schaeffer (1666), compositor de música concreta, replanteó la definición de sonido, ruido y música, sin incluir instrumentos musicales en su Estudio para locomotoras de 1948, por ejemplo. De esta forma, ha llegado a nuestros días este nuevo concepto, aceptado a la par que diversificado y que en opinión de García (2017) "no podemos hablar de campos unificados, ni mucho menos de visiones consensuadas sobre la dimensión epistemológica del sonido" (12).

Diferentes acciones e iniciativas se desarrollan actualmente para estudiar el concepto y determinar sus elementos. Por ejemplo, el artista sonoro y compositor Juanjo Palacios trabaja en el proyecto Mapa sonoru. Escucha Asturias desde 2009, en que se pretende descubrir, conservar y difundir el patrimonio sonoro de Asturias (Mapasonoru 2019). Rhett $A$. Butler, fundador, presidente y 
redactor/editor de la web Mongabay Latam, destaca la necesidad y eficacia en grabar la bioacústica para monitorear la diversidad en bosques tropicales, de igual forma que se utiliza la fotografía por satélite para medir la deforestación (Dasgupta 2019). El artista sonoro Barber (2012) que reafirma su admiración con la escucha de un concierto de batracios los considera como los primeros virtuosos de la biomúsica nunca todavía superados.

Y es que la clasificación del paisaje sonoro como estilo de música podría ser infinito, tantas clasificaciones como formas de vida y sonidos mundanos existen. Citando de nuevo a Barber (2012), tras la publicación de The Tuning of the World, de Murray Schafer (1977), la tachó de "biblia irrefutable e incitadora" (25), y así inició su arte sonoro a través de las campanas urbanas:

Tras construirme un campanario de bolsillo o portativo (1981), se gestará y crecerá en mí un interés en el sonar de las campanas como agente interventor y modulador de paisajes urbanos y sónicos cargados de mensajes bien calendarizados, ritualizados y conformados de todo un vivir, que se expande en el espacio y en el tiempo. (26)

Carles (2019) en el I Encuentro Iberoamericano de Paisajes Sonoros, celebrado en Madrid, asevera que la influencia del músico y el medio debe ser recíproca para el arte sonoro, integrar la estética contemporánea con el ambiente sonoro y lo clasifica de una herramienta didáctica:

El paisaje sonoro es además una valiosa herramienta de sensibilización y educación sonora no solo en el campo musical sino también, en el campo de la educación ambiental. Estos trabajos y sus materiales sonoros resultan eficaces instrumentos de sensibilización pública acerca del carácter estético-musical y social del paisaje sonoro, y su trascendencia para la calidad de vida en la ciudad. Cuando algo se valora, no se desperdicia tan fácilmente.

Además, podríamos añadir que educar la capacidad de emocionarse y poder expresarlo es uno de los retos constantes en la formación de maestros. Al menos, es uno de los objetivos que tenemos en los proyectos educativos de innovación y de investigación, y que aplicamos tanto en clases de grado como en los talleres de la Red de innovación educativa L'Hort/leducarts $3.0(2019)^{1}$ sobre paisaje sonoro. Fomentar el interés o curiosidad de la percepción sensorial y emocional a través de un paisaje repercutirá en la apreciación ante un concierto de música, una obra de arte o cualquier expresión artística, porque ya se han creado las expectativas en la formación. Para ello, aplicamos la escucha activa junto con diversas herramientas de medición y aplicación de las nuevas tecnologías a través de la realidad aumentada y virtual.

También damos valor al sonido urbano, porque, como indica Castro (2018) con su comparativa con la selva, "los dos tienen intensidades y complejidades diferentes, pero siempre con una organicidad imperante" (146). Otondo (2018), además, añade que el estudio de los últimos años de proyectos transdisciplinarios ha obtenido un reconocido logro, como las "dos nuevas normativas ISO sobre paisaje sonoro, que proporcionan criterios para la evaluación cuantitativa y cualitativa de entornos sonoros urbanos, rurales y de fauna silvestre (ISO 2014, ISO 2017)" (131). 


\section{Arte sonoro}

En atención a lo que se concibe como arte sonoro, fue John Cage (1912-1992) quien reveló este arte como una innovación y evolución del lenguaje musical, en aquel entramado de la música contemporánea atonal y dodecafónica del siglo XX entre Arnold Schönberg (1874-1951) e Igor Stravinski (1882-1971). Convivieron, además, diferentes experimentaciones de voces parlantes, elementos mecánicos y sonidos grabados, como la que Varèse y Wen-Chung (1966) explicaban en "The Liberation of Sound", por ejemplo.

Cage (2002) sentó el principio de la obra abierta en que el artista deja fluir la realidad sonora de los objetos con técnicas del azar y la reflexión de la necesidad de silencio; obviedad no manifestada seguramente hasta su aseveración. Silencio se publicó en 2002 en español, del original Silence recopilatorio de artículos editados en 1961 de Cage. Su obra más polémica todavía hoy, 4'33", la define el compositor y estudioso Kyle Gann como "un acto de encuadre, de encerrar sonidos ambientales y no intencionados en un momento de atención con objeto de abrir la mente al hecho de que todos los sonidos son música" (436).

Alumno de Cage fue Allan Kaprow, artista conocido por sus happenings. Con la influencia de Jackson Pollock, aunó vida y arte. Así, en 1959, estrena su primera performance 18 Happenings in 6 Parts en Nueva York, en que, desde una partitura y guion ajustado, se crea un entorno interactivo que conduce a la audiencia a un punto nunca antes conseguido (Schimmel 1998), y baraja las actividades cotidianas con acciones artísticas. Su libro La educación del des-artista (Kaprow 2007) reflexiona sobre la obra de arte al incluir también obras work in progress o experimentos vitales como el no arte. Profesor en diferentes universidades, crea a la par que experimenta y divulga sus teorías, y diferencia cinco modelos de la vida cotidiana en los que encontrar el arte (Andueza 2010). Una de ellos, el modelo de aprendizaje en que da ejemplos de obras que actúan como experiencia o reflexiones, en especial las habituales diarias. Continuando con el concepto de arte sonoro, argumentan Molina y Cerdà (2012):

La primera exposición que emplea esta misma denominación Sound/Art (1983), fue exhibida en The Sculpture Center de la ciudad de New York, y comisariada por William Hellerman, quien plantea que la escucha es otra forma de ver. [...]Y también menciona el manifiesto L'Arte dei rumori de Luigi Russolo, que pretendía recuperar "la vida misma" a través de "conquistar la variedad infinita de los sonidos-ruidos". (1)

En esta escueta concepción histórica del arte sonoro, también debemos incidir en la figura del espectador y en la música en general. Parafraseando a Pitich (2018), en la cadena de decisiones para la performance musical, el oyente entiende el placer musical para sí mismo, según la idea de la reinterpretación en un determinado tiempo y espacio exacto. Del filtro propio de cada uno, de sus conocimientos y comprensión resulta la ejecución de cada interpretación y el mensaje que transmite el ejecutante. Interesante es el pensamiento de Cook (2001) que retoma la teoría sobre la interpretación grupal. La sinergia de los músicos es lo importante de una banda de rock o de una orquesta, añadiríamos. La decisión del músico o del grupo resulta determinante en el momento de la ejecución y de la creación. Es más, la unicidad de la obra de arte musical es cuestionada actualmente, porque estamos reproduciendo con tecnología una partitura (Lizarazu 2019), pero a la par en cada interpretación en vivo es caduca e innovadora.

Según ello, obtenemos el trinomio de autor, ejecutante y oyente para la concepción de un concierto o audición musical en vivo. Y, aun de forma tangencial, tampoco podemos olvidar el entorno y ambiente del concierto, a veces decisivo en nuestra percepción final. 
Por tanto, el arte sonoro es una obra abierta en su acepción de "no definida", que seguramente sea una obra work in progress y que necesita un oyente y entorno activo y adecuado. Esta tesis también nos serviría para el paisaje sonoro. ¿Es esto una casualidad?

Si acotamos geográficamente, en España, las vanguardias musicales y experimentales del siglo XX, encontramos la 17 Edición del Festival de Nitsd'Aielo i Arts celebrado en 2014, donde se realizó un homenaje a los cincuenta años del nacimiento de ZAJ, movimiento de la vanguardia sonora que, como se indicaba en el programa del festival, "se confesaba igualmente musical, pero que dejaba al albur tanto el mismísimo sonar (orquestal o no) como la voluntad (compositiva o no)" (Programa Festival Nits d' Aielo i Arts 2014 2017). Este festival nacía "con la ambición sutil de ser útil y abrir algo más que puertas" (Barber 2013b, 36). El proyecto ZAJ se definía, por tanto, como hijo de Cage y de Fluxus, y apadrinó el nacimiento del festival de música contemporánea Ensems en 1979 que, tras diversas ubicaciones y orientaciones, se mantiene como el más longevo del panorama ibérico. Allí nació también el Grup Actum que a lo largo de diez años mostró “propuestas inauditas en las que el indeterminismo cageano, la electrónica, el gestualismo, la improvisación asintáctica y hasta la creación colectiva eran materia sónica a descifrar oyendo" (Barber 2013a). De estas referencias destacamos nombres de artistas como Carles Santos, Josep Maria Mestres Quadreny, Ana Ricci, Joan Brossa, Llorenç Barber o Fátima Miranda, entre otros.

Barber, siempre muy crítico con la política cultural que abraza el canon clásico de programación musical sin dejar espacio para nuevas vanguardias, es el promotor de varios festivales y diferentes encuentros académicos y artísticos. Es el caso del festival Ensems que antes señalábamos, del que fue su creador, o el Congreso 100 Años de Arte Sonoro Valenciano (1912-2012). Este último contó con el apoyo de Miguel Molina del Laboratorio de Creación Intermedia, del Departamento de Escultura de la Facultad de Bellas Artes de la Universitat Politècnica de València (Gil 2012). De Molina (2007) es la definición de arte sonoro tal vez más completa:

El vocablo arte sonoro (de la traducción anglosajona sound art) empezó a utilizarse a finales de los años setenta del pasado siglo para calificar determinados trabajos de artistas visuales que utilizaban preferentemente el sonido en sus obras, y que no necesariamente estaban basadas en parámetros musicales; y lo que era más importante, que en esta obras sus dos componentes visual y sonoro no podían disociarse, sino que tenían la misma importancia, aspecto este que se separaba claramente del lenguaje audiovisual del cine y vídeo, donde el sonido ha sido a lo sumo un refuerzo de la imagen. Su teorización no se hará hasta la década de los noventa, a partir de exposiciones monográficas sobre el tema en museos y galerías, con la intención doble de enmarcar una nueva práctica artística, y con ello la búsqueda de una identidad diferenciadora con su propia historia y antecedentes, que servirá para su impulso tanto creativo y económico, ya que necesitaba su eco en el mercado artístico para su desarrollo, como así ha sido en los últimos años. (28)

Como se puede apreciar, la inmensidad de ejemplos de arte sonoro que en los últimos años experimentamos y descubrimos en diversos eventos y festivales es proporcionalmente inversa a la atención mediática que suponen. Esta es otra cuestión que ahora no trataremos, pero bastará incidir en algunos ejemplos que de forma soslayada podremos utilizar y, a través de los diferentes festivales, grupos y artistas, enumerar los elementos sonoros que nacen del paisaje. 


\section{Naturaleza y herramientas del paisaje-arte sonoro}

Son cuatro los elementos de la naturaleza: agua, tierra, fuego y aire, junto con un quinto que a veces se añade, el tiempo, u otro como el éter, que enumeraban en la Edad Media, una esencia ligera e imaginaria, de ahí la quintaesencia. En cambio, en China, los cinco elementos que se detallan son tierra, agua, fuego, metal y madera. En la cultura japonesa, se les conoce como godai: tierra, agua, fuego, viento y vacío. De una forma u otra, todos ellos forman el paisaje sonoro y son utilizados de diversas maneras en el arte sonoro. A estos elementos de la naturaleza, debemos añadir los sentidos que son a la vez esenciales en la percepción. Como hemos dicho, no solo disfrutamos del paisaje sonoro por el oído. Entenderemos el arte sonoro según nuestra educación, sensibilidad y ambiente creado para el resto de los sentidos.

Un tipo de reproducción de paisaje sonoro y, por tanto, de arte sonoro que suma diferentes elementos, es el medio audiovisual, aunque con ciertas salvedades. Es verdad que el cine no puede ser arte sonoro, al unir elementos independientes como la música y la imagen, pero ello no excluye algunos ejemplos. Una primera demostración de cine como arte sonoro/ performance es El color de la granada (The Color of Pomegranates, 1969) de Sergei Parajanov, donde la ausencia de diálogos es sustituida con los sonidos del agua, del viento o del recitado de los textos del poeta armenio Sayat-Nova. Destacaríamos en el minuto 5:44 el sonido de las páginas de los libros abiertos mecidos por la brisa.

Un segundo modelo podría ser la película francesa Delicatessen (1991), de Jean-Pierre Jeunet y Marc Caro, comedia negra fantástica, básicamente surrealista y considerada cine de culto por su originalidad. De ella podemos extraer la fuerza visual y sonora de los elementos cotidianos. Basta ver el tráiler promocional en alguna plataforma libre de video. Además del ritmo acompasado en diferentes escenas cotidianas, contiene piezas musicales que se fusionan con las acciones del guion y nos transmite el ambiente sugerente e intrigante de la trama.

Estos dos ejemplos constituyen el paisaje sonoro que vivimos en el día a día, mostrados de forma artística. Y este día a día es el que Ramón Gómez de la Serna llamó “descubrimiento de lo insólito en lo 'trivial', en lo cotidiano" (Zlotescu 1997, 27). Otra cuestión a considerar es que, aunque hayamos empezado por el séptimo arte, no significa que sea reciente la concepción del arte sonoro en el paisaje. Nos contaba Aracil (2019) en el I Encuentro Iberoamericano sobre Paisajes Sonoros:

Los jardines son un refinado artificio diseñado no solo para la vista, el tacto o el olfato, sino también para el oído. La valoración y disfrute consciente de los sonidos en un jardín o en la naturaleza alcanzó en Europa su mayoría de edad en el Renacimiento y Barroco, una época en la que se idearon curiosos mecanismos y estrategias para proporcionar sonidos naturales (el canto de los pájaros) y artificiales (el sonido de las fuentes, la música de autómatas) a escogidos rincones del jardín.

Recordemos también que, en el tratado Musurgia universalis sive Ars magna consoni et dissoni (1650), obra del jesuita alemán Athanasius Kircher, se realizaba tal vez la primera transcripción del canto de las aves. Fubini (2007) destacaba que Kircher hablara todavía de "armonía universal", por ello entendía que la naturaleza del universo no es otra cosa que música perfectísima, de modo que es la primera teoría de los afectos junto con Descartes y su publicación Las pasiones del alma. Es decir, recreamos voluntariamente el paisaje de la naturaleza y la armonía del universo para promover las emociones humanas. 
De igual forma que para Joan Miró (Porpetta 1995) las aves le sirven de enlace entre el mundo terrestre y el mundo celeste, origen de la imaginación, para el compositor Hikari Eo, hijo del escritor y premio nobel Kenzaburo Oé (Fay 2007), el canto de los pájaros le sirvió de conexión para expresarse. Como sabemos, el pequeño Eo nació con diversidad funcional y apenas hablaba o entendía, pero sí reaccionaba con el sonido de los pájaros. Sus padres le consiguieron grabaciones con los trinos y el nombre del pájaro que le correspondía. Y así el niño tuvo la necesidad de expresar que los reconocía. Hoy día, es uno de los autores de clásica más reconocidos de Japón.

El entorno urbano no desmerece esa conjunción emotiva de sonidos. Señala Andueza (2011) que Max Neuhaus fue el artista que fijó el término de instalación sonora y realizó diferentes paseos sonoros en la década de 1960 en los Estados Unidos y Canadá. Neuhaus organizaba

visitas guiadas a plantas generadoras de electricidad para escuchar el sonido de los motores y sentir la vibración en el propio cuerpo. Este y otros paseos sonoros que realizó en Estados Unidos y Canadá entre 1966 y 1976 y agrupó bajo el término LISTEN consistieron mayoritariamente, como la de Vostell y otras, en forzar una consciencia perceptiva del entorno urbano, favoreciendo que la gente pudiera trascender la construcción cultural de la ciudad y sustituirla por otra más personal y conectada a su propia experiencia. (136)

Aunque fue en 1939 cuando el cineasta José Val del Omar creó una instalación sonora en Valencia:

Val del Omar puso en marcha en Valencia el primer Circuito Perifónico de España a finales de 1939. Básicamente se trató de una red de treinta y cinco altavoces distribuidos por algunos de los puntos más importantes de la ciudad a través de los que se difundía una programación diaria que combinaba las inapelables comunicaciones institucionales y doctrinales con noticias, la cartelera, campanadas horarias, música y una creativa publicidad comercial. (Gil 2012,4)

Val del Omar diferenciaba de la radio su Circuito al introducirlo como paisaje sonoro en la ciudad, por lo que constituyó una propuesta de lectura polisensorial, tal y como sugiere Gil (2016). Además del Circuito, Val del Omar inventó varios aparatos sónicos, por lo que bien podríamos considerarlo un artista sonoro. Sánchez (1993) lo recordaba en su visita a su estudio en 1955 como "un poeta del ruido" en que en "una cintita que apenas sirve para atar una caja de bombones... Val del Omar ha metido un concierto de 'música concreta'", con "algunos compases de Falla, sonidos de campanas, golpes de piedra y sonidos de instrumentos de percusión" (112).

El filme Aguaespejo granadino (Val del Omar 1955) se encuentra influenciado por Lorca (que Val del Omar recordaba que le decía "Señor, dame unos oídos para saber escuchar el agua"), y también por Manuel de Falla, que, en sus encuentros hacia 1929 con él, lo animó al uso de las nuevas tecnologías, al decirle: "Yo creo en la música mecánica. Si a mí me dieran una pianola con hipertonos, yo grabaría en el rollo mi música. Así no habría ninguna interferencia del intérprete" (Soria 1992, 123).

Pero volviendo a la instalación sonora, claramente referenciaremos la mecánica y los motores como una de las herramientas más destacadas. Pondremos de ejemplo al artista sonoro sueco Sven-Ake Johansson que estrenó en 1996 el Concierto para 12 tractores. Porque escuchar motores y sentir la vibración que proponía Neuhaus es un elemento recurrente. El vibracionismo, término creado hacia 1916 por Rafael Barradas (Molina 2007), une forma plástica y sonido. Y si buscamos melodía y vibración, tenemos el instrumento rey: el órgano. Este instrumento de teclado engloba todo un sistema mecánico de fuelles y aire, tras siglos de innovación continuada. Pero el órgano mantiene el estatus de instrumento con partitura escrita, por ello, 
no se engloba dentro del arte sonoro, cuestión que se podría replantear, porque, aunque es verdad que no tiene margen de creación musical, sí lo tiene al tener la libertad de seleccionar en ese mismo instante el registro sonoro que elija el intérprete, de modo que es cada versión distinta de un ejecutante a otro con la misma música.

En la época actual, debemos citar la importancia de la tecnología y la electrónica en la música. La electroacústica se inició en la década de 1950, casualmente, paralelo al concepto de paisaje sonoro. El catalán Roberto Gerhard fue uno de los pioneros de la música electrónica con el soporte técnico del taller radiofónico de la BBC londinense. En 1954, estrenó la música incidental The Prisoner, una obra de Bridget Boland, para conjunto de cámara y cinta, seguramente la primera de este género que se escuchó en directo en Gran Bretaña (Duque 2010). Actualmente, son muy irregulares los estudios académicos en España sobre esta materia, pero existen diversos laboratorios que mantienen las investigaciones, y en especial motivadores y reconfortantes son los festivales, como In-Sonora en Madrid que se presenta como una plataforma creada para apoyar y dar visibilidad al arte sonoro e interactivo, o el también mencionado festival Ensems en Valencia.

También es interesante comentar la utilidad que el marketing realiza de la imagen de un sonido. Por ejemplo, la campaña de publicidad de la marca Coca-Cola en la que utilizó recientemente la sinestesia para que a través de la fotografía macro de la superficie de un vaso con la bebida nos lleve con la imaginación al sonido y de ahí directamente a provocar la sed. El lema era Try Not To Hear This. La campaña de DAVID The Agency la titularon The First Print Ads You Can Hear o lo que es lo mismo Los primeros anuncios impresos que podrás escuchar.

\section{Paisaje-arte versus cambio climático}

El contratenor Philippe Jaroussky (1978) sorprendía en 2014 al interpretar arias barrocas a la beluga del Oceanogràfic València. El cetáceo se mostró activo y manifestó diferentes gorjeos y chasquidos, entre los treinta y tres sonidos que son capaces de producir, como un nuevo acercamiento al mundo animal y un inédito intento de lenguaje musical para comprender la naturaleza a la que sentimos cada vez más lejana.

La música cuenta con miles de ejemplos en los que muestra la admiración por la naturaleza. En el segundo libro de madrigales de Claudio Monteverdi (1567-1643), la polifonía para voces Ecco mormorar I'onde es un poema de Torquato Tasso (1544-1595), una forma musical que describe lo que canta, un paisaje que amanece:

\footnotetext{
He ahí las susurrantes olas

y el tembloroso follaje

junto al aura matutina y los arbustos.

$Y$ en las ramas las lindas avecillas

cantan dulcemente

y el oriente sonríe.

He ahí el alba que ya asoma

y se refleja en el mar

y serena el cielo

y el dulce hielo perla los campos
} 
Otro ejemplo lo encontramos en la pieza El grillo de Josquin Des Prez (1450-1521), chançon italiana que sigue las prácticas polifónicas imperantes en el Renacimiento y busca imitar el sonido onomatopéyico del grillo con su música y con el contrapunto imitativo entre sus cuatro voces. ¿Acaso la sociedad evolucionada y tecnológica de ahora no tiene la sensibilidad suficiente para tratar temáticas banales y esenciales de nuestra existencia?

Señalábamos antes la necesidad de educar la capacidad de emocionarse. Deberíamos añadir también la necesidad de educar en los valores primigenios del medio ambiente, intrínsecamente relacionado con la didáctica en integrar el medio ambiente que sugiere Carles (2019) con el paisaje sonoro, antes mencionado.

Volvemos a mencionar a Pauline Oliveros a fin de destacar sus investigaciones con el sonido para poder descubrir más paz interior en medio de la violencia y el malestar de la época, refiriéndose a la guerra de Vietnam. Conocidos son sus estudios de retiro de escucha profunda en las montañas más alejadas de la civilización para la investigación de la conciencia sónica, así como los de adentrase en depósitos subterráneos o en catedrales para inquirir la reverberación del sonido. Y tal vez no fue una concienciación casual sino una evolución histórica que tanto ruido mediático y exceso de contaminación acústica, visual y biológica denotara en Oliveros la necesidad de alertar de los cambios sociales que repercuten en el medio ambiente.

El silencio es un recurso artístico en el cine y en la música. Evocar el silencio que evidenció Cage (2002) en el medio ambiente siempre es motivo de alerta, ya sea un peligro inminente natural, ya sea algo más trágico, como la ausencia de fauna que provoca el hombre a su paso. Pero el silencio de la falta de diálogo en el problema ambiental es indigno para la humanidad y podría ser delito dentro de poco.

El foco mediático en el cambio climático nos descubre los dos problemas ambientales a los que nos referimos que son la depredación ante los recursos y la contaminación ante los residuos (Tommasino, Foladori y Taks 2001). Si los políticos lo permiten, del capitalismo podríamos evolucionar a un desarrollo sostenible. Y esta concienciación engloba la protección de nuestro entorno para las futuras generaciones y una inmediata mayor presencia en el ahora, respectar los recursos y gestionar los residuos. El reconocimiento a nuestra realidad circundante del paisaje natural denotará la capacidad de desarrollar esta afirmación. Y esto solo es posible con la educación.

El arte es una herramienta que demuestra que con la sobreexplotación de recursos naturales y el exceso se modifica el entorno ambiental. Hemos visto cómo reproducimos con la jardinería esos entornos naturales. Resulta obvia la consecuencia ante un ataque vándalo que destroza ese armónico paisaje y ecosistema. Son irrebatibles también las secuelas que tiene ese ataque en nuestras emociones y equilibrio interior. ¿Cómo consentir por tanto ataques al medio ambiente? Iniciado ya el estado de alerta, utilicemos la didáctica del arte para promover el respeto del medio ambiente.

\section{Conclusiones}

En el momento en que un sonido tiene la facultad de transmitirnos una emoción, sea cual fuere, se ha transformado en arte sonoro. No entraremos a detallar la complejidad de este hecho, porque abarca, desde las ondas cerebrales hasta los recuerdos que nos atañen psicológicamente, pasando por magnetismos, rasgos acústicos o simbolismos sociales... obviamente el intervalo sonoro del yo, como indicaba Augoyard (1995), esa reminiscencia 
y querencia es esencial en la percepción final. Por ello, es tan importante en la formación y educación crear expectativas sensoriales. Por tanto, sí podemos enunciar que el paisaje sonoro devendrá un paisaje emocional, y en palabras de Carles (2019): "El concepto de 'paisaje sonoro' permite construir la representación del medio ambiente sonoro como una composición musical".

La especie humana ha tenido que controlar la expresividad de sus emociones para la convivencia. Ha creado una sociedad compleja donde los instintos naturales están comedidos. Y el autocontrol que ha permitido respetar el resto también ha servido a cada individuo para ser respetado. Todos estos inhibidores de las expresiones emocionales han tenido, llamémoslos, efectos secundarios que se manifiestan en detrimento del nivel sensorial, y se apoyan para la comunicación, tal vez en demasía, en sistemas cognitivos. Hay personas con más o menos empatía y diferentes grados de sensibilidad. Sumemos a estos efectos la calidad de vida conseguida, y la ausencia de predadores o de peligros de la naturaleza que alerten a nuestro instinto, así como el exceso de estímulos en la sociedad, tanto sonora como visual. Obtenemos un producto muy artificial y ajeno a la consciencia natural u originaria. Acercarnos nuevamente al sonido cotidiano o paisaje sonoro nos hace volver a nuestra esencia humana. Reeduquemos el respeto por la naturaleza.

“El arte sonoro vuelve a levantar al oyente de su asiento y lo hace transitar en una escucha activa" (Molina y Cerdá 2012, 11). E incluso interactiva si la obra también es táctil. El paisaje natural aúna estas características:

Paisaje sonoro y sus derivaciones de mapas sonoros y de experiencias sonoras geolocalizadas, que han permitido un diálogo activo de ese oyente móvil, que cambia su escucha (y con ello su concepción del entorno) en su propio transitar, ya sea urbano o natural, más allá de salas de concierto o de espacios destinados al arte. (11)

Retomemos nuestra pregunta inicial de la ordenación primogénita de los sonidos. Si se descubren los teoremas matemáticos y también la diversidad de tonalidades musicales, ¿revelamos por tanto la música?, ¿o creamos la melodía ordenando el sonido?, ¿nos inventamos esas secuencias de compases?, ¿o desciframos los códigos de la naturaleza? Lejos de ser una paradoja paralela, es demostrable que las dos afirmaciones son certeras. Siempre podremos emplear las fórmulas para los análisis en la relación entre dos variables. Y aplicaremos los tratados y las teorías de los afectos en las composiciones musicales o cualquier paisaje sonoro.

En nuestro planteamiento, nos preguntábamos si el paisaje sonoro era arte sonoro. La respuesta cumple en 2019 los cincuenta años en formato libro: la edición en español de la editorial Ricordi de El nuevo paisaje sonoro: un manual para el maestro de música moderno de R. Murray Schafer.

En todos los casos hay debate, y tenemos aquí la contrarréplica, si buscamos las divergencias entre música y arte sonoro que, en opinión de Reyes (2006), solo coinciden en el punto acústico:

Mientras en la música se habla de una semántica de melodía, armonía, orquestación y contrapunto, en el arte sonoro se persigue el espectro de un sonido, la intervención espacial con la dispersión de la onda, la disposición de fuentes sonoras además de muchas otras cualidades espectrales que se adjuntan formando un trabajo de condiciones artística. (58) 
En nuestra teoría planteada, si el sonido transmite emoción, es, por tanto, arte sonoro, tal y como lo hace el paisaje sonoro. Así, hemos acotado una definición símil de paisaje sonoro y arte sonoro, que podríamos resumir como una obra abierta en su acepción de "no definida", que seguramente sea una obra work in progress y que necesita de un oyente activo y un entorno adecuado para que se produzca el hecho artístico, de modo que es cada actuación única y excepcional y, por ende, el resultado surge a la par que se crea. Los procesos y las combinaciones son infinitos, como sugirió Pitich (2018). No hay mayor grandeza musical que el universo natural. Es necesario inducir a los oyentes a percibir vibraciones en las que antes no reparaban y a escuchar sonidos de su propio ambiente, de su nuevo paisaje sonoro. El universo es vuestra orquesta (Schafer 2012).

\section{NOTAS}

1. Proyecto Red de innovación L'Hort/leducarts 3.0 (UV-SFPIE_GER18-849158) del Vicerrectorado de Políticas de Formación y Calidad Educativa de la Universitat de València. 
[REFERENCIAS]

Aguaespejo granadino. Dirigido por José Val del Omar. 1955; España. Documentary.

Andueza Olmedo, María. 2011. “Creación, sonido y ciudad: un contexto para la instalación sonora en el espacio público". Tesis doctoral, Universidad Complutense de Madrid.

- 2011. "A las ciudades se las conoce, como a las personas, en el andar: orígenes de la instalación sonora en el espacio público en el marco del urbanismo y la sociología de los años 60". Arte y Políticas de Identidad 7: 127-142.

Aracil, Alfredo. 2019. “Un poco de historia: diseños sonoros en los jardines del

Augoyard, Jean-François. 1995. "La sonorización antropológica del lugar". En Hacia una antropología arquitectónica, compilado por Mari-Jose Amerlinck, 205-219. Jalisco: Universidad de Guadalajara.

Barber, Llorenç. 2012. “Contextualizando el congreso 'cien años de arte sonoro en Valencia'". En 100 anys d'art sonor valencià, de Llorenç Barber y Monserrat Palacios, 1-54. Valencia: Universitat Politècnica de València.

- 2013b. "Contextualizando el congreso 'cien años de arte sonoro en valencia'". En XV Festival Nits d'Aielo i Art: Congreso100 años de Arte Sonoro Valenciano, 10-69. Valencia: Universitat Politècnica de València.

Botella Nicolás, Ana María y Amparo Hurtado Soler. 2016. “Innovación docente en el grado de maestro de la Universitat de València: la percepción auditiva y visual del paisaje a través de las TIC". Revista Opción 32 (7): 215-230.

Cage, John. 2002. Silencio. Madrid: Árdora.

Carles, José Luis. 2019. "El paisaje sonoro, una herramienta interdisciplinar: análisis, creación y pedagogía con el sonido". Consultado el 8 de octubre de 2019. https://cvc.cervantes.es/artes/paisajes_ sonoros/p_sonoros01/carles/carles_01.htm

Castro Solano, M. M. Otto. 2018. “La ciudad como fuente de sonidos para la creación sonora". Resonancias 22 (42): 143-150.

Cook, Nicholas. 2001. "Between Process and Product: Music and/as Performance". Music Theory Online: The Online Journal of the Society for Music Theory 7(2): 1-24.

Dasgupta, Shreya. 2019. “Escuchando a escondidas: la bioacústica resulta efectiva para monitorear la diversidad en bosques tropicales". Mongabay. 19 de febrero. Consultado el 20 de mayo de 2019. https:// es.mongabay.com/2019/02/bioacustica-bosques-tropicales/

Delicatessen. Dirigido por Jean-Pierre Jeunet, Marc Caro, Gilles Adrien. 1991; Francia: UGC / Hachette Première, 1991. Fim.

Duque Olmedo, Carlos. 2010. “Gerhard's Electronic Music: A Pioneer in Constant Evolution". Ponencia presentada en Proceedings of the 1st International Roberto Gerhard Conference, Huddersfield, Reino Unido, 27-28 de mayo.

El color de la granada. Dirigido por Sergei Parajanov. 1969; Unión Soviética: Armenfilm Studios, 1969. Film.
Fay, Sarah y Kenzaburō Ōe. 2007. "The Art of Fiction No. 195". Paris Review 183: 37-65.

Fubini, Enrico. 2007. “Razón y sensibilidad: lo sacro y lo profano en la musicalidad del siglo XVII". Quaderns de filosofia i ciència 37: 1-78.

García Castilla, Jorge David. 2017. "Musicología musical: la música y el sonido como medios de investigación crítica". El Oído Pensante 5 (1): 1-30.

Gil Noe, José Vicente. 2012. "XV Festival Nits d'Aielo i Art. Congreso: 100 años de Arte Sonoro Valenciano". Arte y Políticas de Identidad 6: 263-268.

— 2013. "Un altavoz en las torres, imagen del festival nits d'aielo i art: José Val del Omar y su paso 'sonoro' por Valencia". En XV Festival Nits d'Aielo i Art: 100 años de arte sonoro valenciano. Valencia: Universitat Politècnica de València.

- 2016. "Prácticas musicales y sonoras experimentales en Valencia durante el siglo XX, 1922-1983: de olvidadas a precedentes del arte sonoro valenciano". Tesis doctoral, Universitat de València.

Kaprow, Allan. (2007). La educación del des-artista. Traducido por David García Casado y Armando Montesinos. Madrid: Árdora Exprés.

Lizarazu González, Haize. 2019. "Extended performer. Evolución y cambio de rol del intérprete musical: hacia una música expandida". Cuadernos de Música, Artes Visuales y Artes Escénicas 14 (1): 115-127.

Mapasonoru. 2019. "Mapa sonoru. Escucha Asturias". Consultado el 20 de mayo de 2019. http://mapasonoru.com/acerca-de.php

Molina Alarcón, Miguel. 2007. “Ecos del arte sonoro en la vanguardia histórica española (1909-1945)". En / Muestra de arte sonoro español, compilado por José Iges, 28-71. Lucena: Weekend Proms.

Molina Alarcón, Miguel y Josep Cerdà i Ferré. 2012. “Entre el arte sonoro y el arte de la escucha". Arte y Políticas de Identidad 7: 1-4.

Otondo, Felipe. 2018. "Paisajes sonoros reales e imaginarios". Resonancias 22 (42): 131-141.

Pitich, Mauricio Andrés. (2018). “Cadeia de decisões na performance musical". El Oído Pensante 6 (2): 100-115.

Porpetta, Antonio. 1995. "El mundo sonoro de Gabriel Miró". Tesis doctoral, Universidad Complutense de Madrid.

Programa Festival Nits d’ Aielo i Arts 2014. (2017). “17 Edición del Festival Nit d'Aielo i Arts -De Basuras y Esperanzas- 2014 Programa completo del Festival". Consultado el 8 de octubre de 2019. https://issuu.com/ freezia-studio/docs/programa_nits_ld2

Reyes, Juan. 2006. "Perpendicularidad entre el arte sonoro y la música". Cuadernos del Centro de Estudios 20: 57-77.

Rocha Iturbide, Manuel. 2019. "La escucha como forma de arte". Sulpunticello 64: 1-19.

Sánchez, Alfonso. 1993. "La noche estaba metida en agua. Informaciones. Diario de la tarde". En Val del Omar sin fin, editado por Gonzalo Sáenz de Buruaga y María José Val del Omar, 112. Granada: Diputación Provincial de Granada. 
Soria, Florentino. 1992. "Declaraciones de Manuel de Falla en boca de Val del Omar. La Estafeta Literaria no 46 (1956)". En Val del Omar sin fin, editado por Gonzalo Sáenz de Buruaga, 123. Granada: Diputación Provincial de Granada.

Schafer, Murray. 1977. The Tuning of the World. Toronto: McClelland and Stewart.

— 2011. Limpieza de oídos. Buenos Aires: Melos.

- 2012. El nuevo paisaje sonoro: un manual para el maestro de música moderno. Traducido por Juan Schultis. Buenos Aires: Melos.

Schaeffer, Pierre. 1966. Traité des objets musicaux. París: Le Seuil.

Schimmel, Paul. 1998. "Leap into the Void: 'Performance and the Object'". En Out of Actions: Between Performance and the Object, 1949-1979, 17-119. Nueva York/Londres: MoCA Los Angeles.

Tommasino, Humberto, Guillermo Foladori y Javier Taks. 2001. "La crisis ambiental contemporánea". En Sustentabilidad, 9-26. México: Universidad Autónoma de Zacatecas.

Varèse, Edgard y Chou Wen-Chung. (1966). "The Liberation of Sound". Perspectives of New Music (5) 1: 11-19.

Zlotescu, loana. 1997. "Definiendo el 'sistema estético' del ramonismo". En Obras completas III: Ramonismo I. El Rastro. El circo. Senos (1914-1917), de Ramón Gómez de la Serna, 27-28. Barcelona: Galaxia Gutenberg. 